\title{
Letter concerning "Enzyme replacement therapy in a patient with Fabry disease and the development of IgE antibodies against agalsidase beta but not agalsidase alpha", by Tanaka et al.
}

\author{
Gabor E. Linthorst • Johannes M. F. G. Aerts
}

Received: 13 July 2010 /Revised: 20 September 2010 /Accepted: 23 September 2010 /Published online: 12 October 2010

(C) The Author(s) 2010. This article is published with open access at Springerlink.com

Dear editor,

Recently, Tanaka and co-workers published a report in the Journal of Inherited Metabolic Disorders on the treatment of a young male with Fabry disease who developed an immunoglobulin E ( $\mathrm{IgE}$ ) response toward one of the two available enzyme preparations (agalsidase beta) but not to the other (agalsidase alpha) (Tanaka et al. 2010). As has been shown by several groups, the emergence of $\operatorname{IgG}$ antibodies toward the infused enzyme alpha galactosidase occurs frequently in male Fabry disease patients (Linthorst et al. 2004; Whitfield et al. 2005; Ohashi et al. 2007), irrespective of the enzyme preparation used. In these studies, cross-reactivity was shown: in anti-agalsidase IgG-positive patients, these antibodies were always equally reactive toward either agalsidase alpha or beta, again irrespective of the enzyme preparation given to the patient. The presence of anti-agalsidase $\operatorname{IgG}$ results in less urinary GL-3 clearance and is associated with infusion-associated events (Linthorst et al. 2004, 2006).

The study by Tanaka et al. is interesting for two reasons: First, the patient had a known severe atopy, and this led the authors to decide to monitor anti-agalsidase $\operatorname{IgG}$ and $\operatorname{IgE}$ levels routinely between infusions. Following the first

Communicated by: Douglas A. Brooks

G. E. Linthorst $(\bowtie)$

Department of Endocrinology and Metabolism, Academic

Medical Center,

Meibergdreef 9,

1105 AZ Amsterdam, The Netherlands

e-mail: g.e.linthorst@amc.nl

J. M. F. G. Aerts

Department of Medical Biochemistry, Academic Medical Center,

Meibergdreef 9,

1105 AZ Amsterdam, The Netherlands infusion of agalsidase beta of $1 \mathrm{mg} / \mathrm{kg}$, a positive antiagalsidase beta $\operatorname{IgE}$ result was obtained. The authors do not mention the anti-agalsidase IgG status. The emergence of anti-agalsidase IgE after the first infusion is remarkably early, as most anti-agalsidase (IgG) antibodies will be detectable between infusions four and 12 (e.g., months 2-6). The patient's atopy may have contributed to the early immunization toward agalsidase beta. Second, this is the first case in which no cross-reactivity is reported for antibodies between agalsidase beta and alpha. Unfortunately no antiagalsidase $\operatorname{IgE}$ titers are mentioned, and it is not known how the authors determined anti-agalsidase IgE. Was the same assay employed using the two different enzymes to capture (and determine) the actual presence of anti-agalsidase IgE? Did the authors use an in-house assay, or was the antibody status measured by the respective manufacturers of agalsidase alpha and beta? As a service to the medical community, both producers of agalsidase alpha (Replagal, Shire Inc.) and beta (Fabrazyme, Genzyme Corp.) measure anti-agalsidase IgG and IgE in plasma from patients treated with their products. Substantial differences on the presence (or absence) of antiagalsidase IgG in the assays employed by the two companies have become apparent. This observation resulted in an initiative to develop a uniform method to measure, quantify, and report antibody status (Schellekens 2008). This initiative is sponsored by the two involved companies and is joined by several academic laboratories. Its results are eagerly awaited. Such a uniform assay will aid greatly the ability to discern possible differences in antibody response toward the two products.

The possibility that some anti-agalsidase $\operatorname{IgG}$ or $\operatorname{IgE}$ antibodies may not be cross-reactive offers hope for those who develop such antibodies and subsequently may develop severe infusion reactions or reduced efficacy. However, it is imperative that the findings of Tanaka et al. 
be substantiated in a uniform assay expressing agalsidase alpha and beta. Only then can a true comparison be made.

Open Access This article is distributed under the terms of the Creative Commons Attribution Noncommercial License which permits any noncommercial use, distribution, and reproduction in any medium, provided the original author(s) and source are credited.

\section{References}

Linthorst GE, Hollak CEM, Donker-Koopman WE, Strijland A, Aerts JMFG (2004) Enzyme therapy for Fabry disease: Neutralizing antibodies toward agalsidase alpha and beta. Kidney International 66(4):1589-1595
Linthorst GE, Vedder AC, Ormel EE, Aerts JM, Hollak CE (2006) Home treatment for Fabry disease: practice guidelines based on 3 years experience in The Netherlands. Nephrology, Dialysis, Transplantation 21(2):355-360

Ohashi T, Sakuma M, Kitagawa T, Suzuki K, Ishige N, Eto Y (2007) Influence of antibody formation on reduction of globotriaosylceramide (GL-3) in urine from Fabry patients during agalsidase beta therapy. MolGenetMetab 92(3):271-273

Schellekens H (2008) The immunogenicity of therapeutic proteins and the Fabry antibody standardization initiative. Clinical therapeutics 30(Suppl B):S50-S51

Tanaka A, Takeda T, Hoshina T, Fukai K, Yamano T (2010) Enzyme replacement therapy in a patient with Fabry disease and the development of $\operatorname{IgE}$ antibodies against agalsidase beta but not agalsidase alpha. J Inherit Metab Dis [Epub ahead of print]

Whitfield PD, Calvin J, Hogg S et al (2005) Monitoring enzyme replacement therapy in Fabry disease-role of urine globotriaosylceramide. J nherit Metab Dis 28(1):21-33 